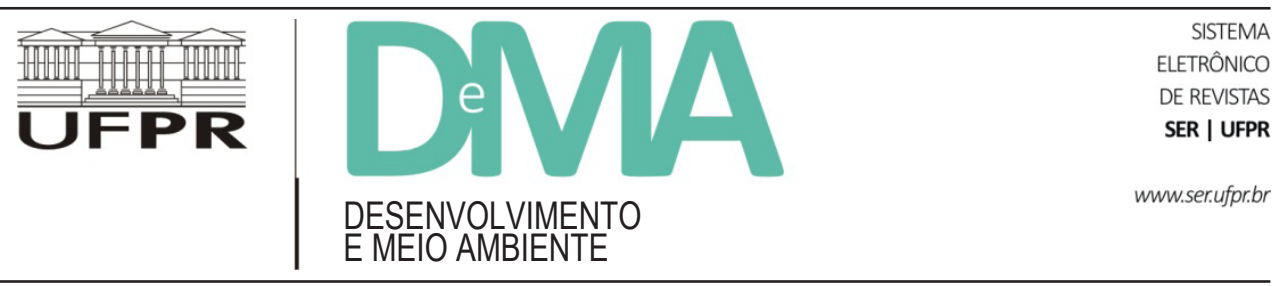

\title{
Homenagem do Programa de Pós-Graduação em Desenvolvimento Rural - PGDR da UFRGS ${ }^{1}$
}

É com imenso pesar que a Coordenação do Programa de Pós-Graduação em Desenvolvimento Rural (PGDR) comunica o falecimento da professora Magda Maria Zanoni, ocorrido na cidade de Paris, França, na madrugada do dia 10/03/2015.

A professora Magda, docente pesquisadora associada no PGDR, possuía graduação em Ciências Biológicas pela Universidade Federal do Rio Grande do Sul e doutorado em Sociologia pela Université Paris 1 (Panthéon-Sorbonne). Desempenhou funções como Maitre de Conférences na Université de Paris VII - Université Denis Diderot e assessorou o Ministério do Desenvolvimento Agrário (MDA). Em reconhecimento a sua intensa atuação junto ao Programa de Doutorado Interdisciplinar em Meio Ambiente e Desenvolvimento (MADE), recebeu o título de Doutor Honoris Causa da Universidade Federal do Paraná (UFPR).

Sua trajetória acadêmica veio sempre acompanhada de uma incansável militância social, inscrevendo e alimentando discussões sobre uma "Ciência Cidadã". Dedicou-se, por vários anos, a aprofundar o diálogo e a concretizar a cooperação entre o Brasil e a França, entre instituições acadêmicas e, também, entre organizações de agricultores. Sua atuação pautava-se por ações inovadoras e na busca pela construção de novas abordagens sobre a ciência, em particular nas articulações entre pesquisa e formação.

Autora de estudos do NEAD sobre temas relacionadas à biotecnologia e aos impactos dos organismos geneticamente modificados para a sociedade, a economia e o meio ambiente, Magda também foi fundadora do Grupo de Estudos em Agrobiodiversidade do Ministério do Desenvolvimento Agrário (GEA).

Na UFRGS, além de sua atuação junto ao Programa de Pós-Graduação em Desenvolvimento Rural (PGDR), desempenhou atividades junto ao curso de graduação a distância em Desenvolvimento Rural (PLAGEDER), ao Grupo de Pesquisa Interdisciplinar Meio Ambiente e Desenvolvimento (GRIMAD) e a Faculdade de Agronomia (Projeto Residência Agrária).

\footnotetext{
${ }^{1}$ Disponível no site: https://journals.openedition.org/confins/10190
} 